\title{
Complex and comprehensive method for reliability calculation of structures under fire exposure
}

\author{
Authors: \\ Tamás Balogh ${ }^{\mathrm{a}}$, László Gergely Vigh ${ }^{\mathrm{b}}$ \\ a Budapest University of Technology and Economics, Department of Structural Engineering, H-1111 \\ Budapest, Mủegyetem rkp. 3, Hungary, baloghtamas@epito.bme.hu \\ ${ }^{\mathrm{b}}$ Budapest University of Technology and Economics, Department of Structural Engineering, H-1111 \\ Budapest, Müegyetem rkp. 3, Hungary, vigh.l.gergely@epito.bme.hu \\ Corresponding author: \\ Tamás Balogh \\ Budapest University of Technology and Economics, \\ Department of Structural Engineering, \\ H-1111 Budapest, Mủegyetem rkp. 3, HUNGARY, \\ Tel.: +36-1-463-1741; Fax: +36-1-463-1784 \\ baloghtamas@epito.bme.hu
}

\section{Proposed referees:}

Greg Baker

Chief Scientist

SP Fire Research AS

Box 4767 Sluppen, NO-7465 Trondheim, Norway

Tillerbruveien 202, NO-7092 Tiller, Norway

Phone: (+47) 93001227

E-mail: greg.baker@spfr.no

Abbie Liel, Ph.D. P.E. 


\author{
Assistant Professor \\ Dept. of Civil, Environmental and Architectural Engineering \\ University of Colorado - Boulder \\ Phone: (+1) 3034921050 \\ Email: abbie.liel@colorado.edu
}

\begin{abstract}
The reliability of structural systems has to be verified against failure caused by extreme effects, such as fire and seismic effects. To the best of the authors' knowledge, there is a lack of studies in the literature on comprehensive reliability calculation of complex structural systems; the available studies mainly deal with the reliability calculation of simple, separated elements. In this study, a methodology is presented for the calculation of reliability of structures under fire exposure, giving a more complex and comprehensive basis for the calculation of structural reliability than earlier studies in the literature: a) the reliability calculation does not focuses on one single element but the whole structure; b) the presented methodology is able to consider any type of fire curve; c) reliability analysis includes the nonlinear analysis of the structure, in this way the highly nonlinear structural response is followed; d) the structural reliability is assessed on time basis. The applicability of the proposed algorithm is presented through reliability calculation of tapered portal frame structure protected by intumescent coating, as an example structure. The probability of failure is calculated using First Order Reliability Method. The resulted probabilities are verified using Monte Carlo Simulation.
\end{abstract}

\title{
1. INTRODUCTION
}

There are different opinions among engineers and researchers on the achievable level of fire safety using prescriptive codes due to the simplified modelling of fire effect and structural resistance calculation in the standards, e.g. in MSZ EN 1991-1-2:2005 (EC1-1-2) and MSZ EN 1993-1-2:2013 (EC3-1-2) [1, 2]. To guarantee the appropriate structural reliability (almost a synonym for safety, practically the probability that no failure will happen in a certain design situation) is particularly important because of the life safety requirement, however, both the too conservative and unreliable design is unfavourable for the economy and society. The reliability problem related to fire design situation is inherently highly uncertain; a 
significant part of uncertainties comes from the high nonlinearity (nonlinear and time-dependent material properties, stability failure modes, nonlinear temperature-time relationship, etc.) and complexity (large number of influencing design variables, modelling of complex structural response, etc.) of the design problem. The above discussed difficulties and the studies from the literature review point out the necessity of further research in this area in order to develop tools assessing the structural reliability more accurately than it was possible earlier. As to the literature, in an earlier study Holicky et al. [3] analysed the reliability of unprotected simple supported steel beams with Second Order Reliability Method (SORM) [4], which had been verified according to EC3-1-2 [2]. Jeffers et al. [5] analysed protected simple supported steel beams as well using both ISO standard fire curve (equivalent fire effect that is commoly used for fire design given in temperature vs. time format) [43] and EC1-1-2 conform parametric fire curves (Eurocode conform curves that are obtained on the basis of the properties of the compartment and the combustible material) to model the temperature in the compartment. The reliability of the beam was assessed using Monte Carlo Simulation (MCS) with Latin Hypercube Sampling (LHS). They pointed that probability calculation is needed to ensure the consistent reliability level in the fire resistant design and further discussion is necessary in order to decide the acceptable level of risk in structural fire engineering. Guo and Jeffers [6] presented a detailed discussion on the reliability calculation theory extended for calculation of the failure probability under fire exposure. They calculated the reliability of a simple pinned column with FORM (First Order Reliability Method), SORM and MCS [4]. The failure mode of the protected steel column was stability failure, namely the lateral buckling phenomena, which was controlled through deformation constraint at the middle node of the element. Based on the resulted probabilities they have showed that there can be significant difference between MCS and FORM, where FORM resulted more conservative failure probabilities. Li et al. [7] investigated the reliability of steel column elements protected with intumescent coating. They applied equivalent time concept [1], thus the fire effect was modelled with ISO standard fire curve. Based on their results, they were able to assess the aging effect of the intumescent coating for the structural reliability. 
Lange et al. [8] have written an interesting paper on the reliability calculation of structures under fire exposure using the framework of Pacific Earthquake Engineering Research Center (PEER), which was originally developed for Performance Based Seismic Engineering (PBSD). A composite steel floor system was analysed in their study. They applied the maximum temperature of the compartment (which is calculated using parametric fire curve) as the intensity measure, therefore the calculated probabilities are not related to time which is actually an important measure in fire safety engineering.

Reliability analysis of complex structures can be found in [9] and [10]. In the first study Boko et al. analyzed an unprotected steel roof structure with SORM and FORM. They pointed that using rules and recommendations from EC1-1-2 and EC3-1-2 appropriate safety level can be ensured. The analysed truss structure was not taken into account as structural system, the presented reliability indices are related single elements. In the second study, Boko et al. presented the analysis of a steel portal warehouse without fire protection. The reliability related to the failure of the beam was obtained with different parametric fire curves [1] calculated using different values for fuel load, fire area and opening factor. They pointed that the usage of ISO standard fire curve leads for conservative results related to the structural reliability due to the large compartment size of the investigated structure.

In case of reinforced concrete structures, the research of the structural reliability is also a developing area. Eamon and Jensen in [11] presented the investigation of prestressed, simple supported reinforced concrete beam exposed to fire. For the reliability calculation they used MCS. Their results showed among others the effect of live load ratio, concrete cover, reinforcement ratio and the type of fire curve on the structural reliability. In other studies $[12,13]$ they presented the reliability analysis of reinforced concrete columns and conventional beams. Colie et al. [14] analysed simple supported one-way concrete slabs using ISO standard fire model. They calculated the ignition probabilities in consistent with the standardized constraint for the structural reliability and they found good agreement with available statistical values from the literature. 
It can be concluded that structural reliability calculation under fire exposure is still a developing area and because of some shortcomings the available studies do not ensure strong and consistent basis related to the reliability level of different structures that were designed using prescriptive rules from modern codes (e.g. [1]). For example, the application of different fire curves in the above listed studies is clearly a limitation of the results. To ensure uniform reliability level with using different fire curves is questionable due to the differences e.g. in the heating velocity and maximal compartment gas temperatures. It is recommended to model the fire effects as accurate as possible in the design process. For example, ISO standard fire curve can be considered only as a non-realistic, comparable effect which can barely be the basis of realistic reliability calculation. Nowadays, one or two zone model calculations [15] can be the best alternatives. Furthermore, the fact that the structural reliability in a lot of cases is ensured through the verification of detached structural elements without interaction makes the safety level related to the whole more uncertain. In some cases, even in the available literature, the studies on the investigation of the standardized reliability level confine themselves on analysing the reliability level of simple elements (typically simple supported beam elements) neglecting e.g. the interaction of different elements in a statically indeterminate structure or plastic design. It seems evident that in case of complex structural systems, the reliability of the structure is rarely equal with the reliability of one of its elements. More accurate information can be achieved with the modelling the whole structure and follow the nonlinear structural response under high temperature considering the spatial deviation of the temperature.

The global aim of this paper is to propose a tool that is able to deal with the discussed difficulties and to provide more accurate information on structural reliability for structures under fire exposure. The proposed methodology is inherently applicable for any kind of structure that can be analysed as a system with modelling its nonlinear behaviour and not only as a totality of separated elements. The methodology gives the opportunity to apply more realistic and problem dependent fire curves. For the time being, similar framework is not available in the literature. The application of proposed methodology is illustrated through an example structure, namely a tapered portal frame structure protected by intumescent painting. 
FORM is implemented in the framework due its effectiveness and reasonable accuracy. A given frame structure which has been designed according to prescriptive code, namely MSZ EN 1990:2011 (EC0), EC1-1-2 and EC3-1-2 [16, 1, 2] is studied. The accuracy and the sensitivity of the calculation are assessed by comparing the MCS results.

\section{PROPOSED METHODOLOGY}

The proposed methodology is illustrated in Fig. 1 with the help of tapered steel frame as an example structure throughout the paper. The reliability analysis is part of a Bayesian probabilistic network [4], where the probability of severe fire is accounted. While calculation of failure probability and Bayesian networks are straightforward and well known, the suggestions of the authors are concentrated mainly in the composition of the limit state function and the whole framework. The limit state function, illustrated in Fig. 1, has the following steps in one iteration step of FORM reliability analysis (these steps are described in more detailed form in the referred section): 1) modelling of the fire effects; 2) calculation of the steel temperature; 3) nonlinear structural analysis; 4) check the failure modes; 5) evaluation of $G(\mathbf{x}, t)$ function:

$$
G(\mathbf{x}, t)=1-\frac{t}{t_{R}}
$$

Where the $t, t_{R}$ and $\mathbf{x}$ are the time (where the time demand shall be substituted), the time capacity and the vector of discrete design variables, respectively. The calculation of $t_{R}$ is based on the loss of load bearing capacity of the elements. The point of failure is equal with the time step where the utilization of the frame exceeds 1.0. This point gives the fire resistance capacity of the structure in time unit, and as it is shown in Fig. 1, the limit state function is formulated on time basis contrary to other studies $[6,7,9,10]$ where steel or maximum gas temperature, internal force or displacement is used for this purpose. First of all, it is practical to use the time as a measure of capacity and demand due to the fact that the interest of the designer is focused on the reliability according to the stability of the structure within the required time of evacuation, which is given by national or international standards. Using of the maximum gas temperature in the compartment and capacity temperature to formulate the limit state function is not so informative 
from point of view of life safety criteria, probably when the designer is interested in other performance levels, e.g. no collapse requirement for some reason. The internal forces to calculate the value of the limit state function can be used solely in case separated elements not in case of a complex structure thus the use of internal forces would overcomplicate the reliability calculation and separated reliability analysis would be necessary for every failure components with the consideration of the possible correlation.

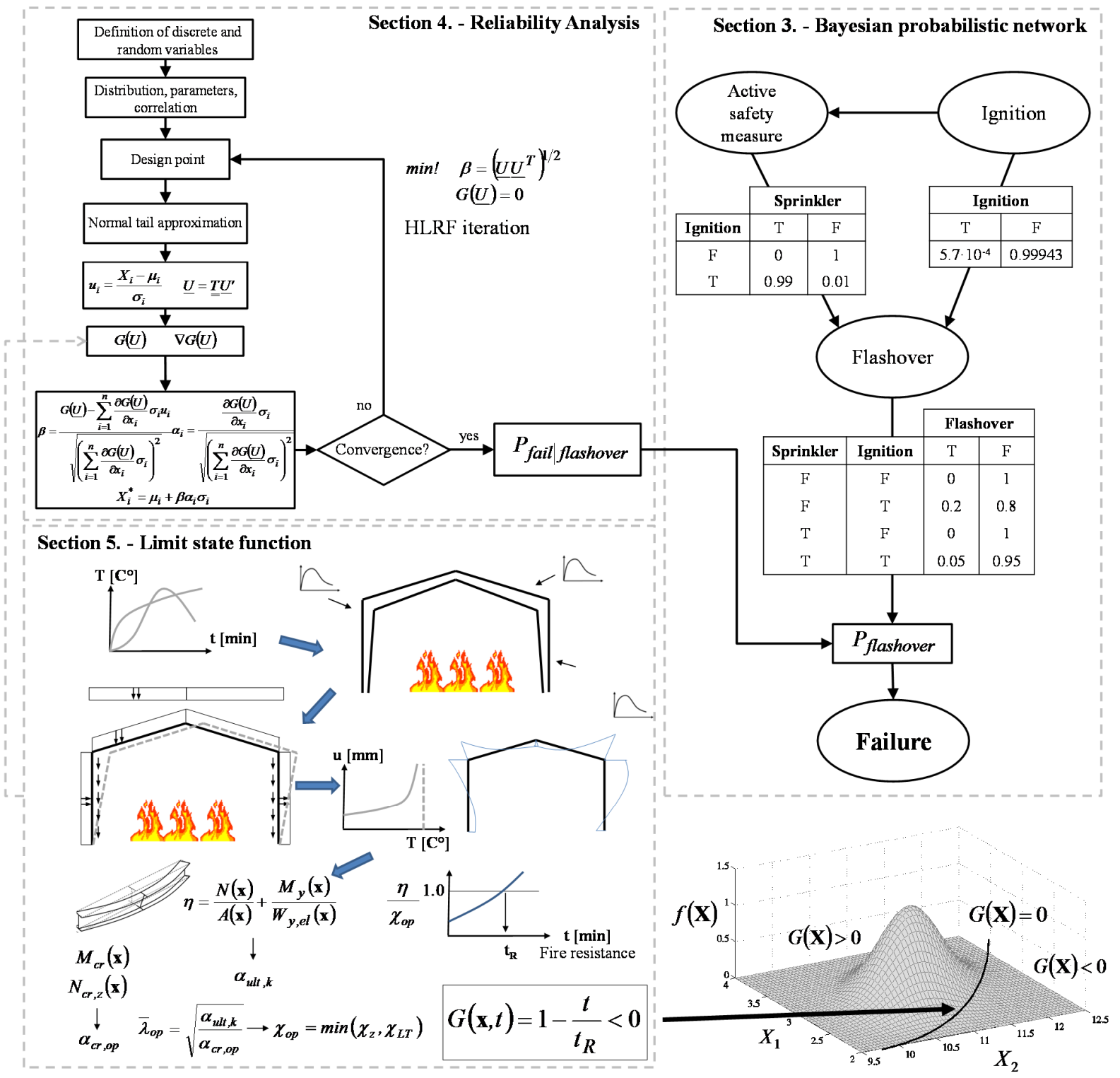

Fig. 1. - Overview from the proposed methodology and the limit state function 
Fig. 1 is also an outline of this paper, the individual parts are discussed in more detailed from in the referred sections using a tapered steel frame as an example. The parts can be replaced or extended where appropriate if another type of structure is studied.

\section{BAYESIAN PROBABILISTIC NETWORK}

The result of the reliability analysis is a conditional probability which says what the probability of failure is when the so-called flashover (simultaneous ignition of most of flammable material in a compartment) occurs. For this reason, the probability of occurrence of flashover also has to be taken into account. A quite simple Bayesian probabilistic network [4] is implemented in the proposed framework (shown in Fig. 1 where $\mathrm{F}$ and $\mathrm{T}$ refer to false and true events, respectively) in order to take into account the ignition occurrence, the effect of active safety measures by the calculation of the probability of flashover. However the user can extend the network to consider other effects not accounted here. A more refined net can be found in [17] for risk assessment in fire resistant design.

The ignition probability can be assessed using statistical data [18] or can be approximated using fault trees. Relevant data can be found in the literature $[19,20]$ according to the effectiveness of the active safety measures (e.g. sprinkler system, detection by heat, etc.) and the possibility of fire growth from ignition for different functions. For the design problem which is investigated in this paper, the probability of ignition and fire growth is assumed to be equal with $P(I)=10 \cdot 10^{-7} /\left(\mathrm{m}^{2} \cdot\right.$ year $)$ for an industrial building based on [19], while it was accounted that the a detection system is deployed and can cut down the fire growth probability on the quarter of the original value [19]. The effect of the service life is accounted with the assumption that the ignitions in different years are independent. A considerably low 0.01 probability is considered according to the failure of the detection system. The designed frame is located maximum 30 minutes from the closest professional fire department, thus another decreasing constant could be considered with the value of 0.2 [19].

As it can be seen, active safety measures are resulting safer solutions by decreasing the possibility of ignition and flashover. The calculated flashover probability is equal with $P_{\text {flashover }}=0.0018$ for 50 years. It is 
interesting to note that through the ignition and development of the fire structural reliability actually depends on the function of the investigated building, so it seems that the usage of equivalent fire effects (e.g. ISO fire curve) may not lead homogenous reliability level. When other active safety measures are applied, e.g. sprinkler system, the reliability level can be significantly increased and it can happen that it may be not necessary to apply passive fire protection. The optimal solution can be selected only on the basis of cost and risk analysis.

\section{RELIABILITY ANALYSIS}

The aim of reliability analysis is mainly to obtain the probability of failure $\left(P_{f}\right)$ of the investigated structure. The structural failure is modelled with the so-called limit state function, $G(\mathbf{X})=0$ in Fig. 1, which separates the safe $(G(\mathbf{X})>0)$ and unsafe $(G(\mathbf{X})<0)$ potential solutions. Basically, the ratio of safe solutions to the all possible solutions gives the reliability of the structure in a given design situation $\left(R=1-P_{f}\right)$. This is theoretically equal with the value of the following integral if the distribution of the random variables can be approximated with continuous distribution functions.

$$
P_{f}=P\{G(\mathbf{X})<0\}=\int_{G(\mathbf{X})<0} f(\mathbf{X}) d \mathbf{X}
$$

Where the $f(\mathbf{X})$ is the joint density function, which already contains the random variables from the effect and resistance side. In case of normally distributed joint density function, the integral can be evaluated in the following way.

$$
P_{f}=\Phi\left(-\frac{\mu}{\sigma}\right)=\Phi(-\beta)
$$

Where, $\mu, \sigma$ and $\boldsymbol{\Phi}(-)$ refer to mean, standard deviation and cumulative distribution function of standard normal distribution and $\beta$ is the so-called reliability index (frequently used in literature as the measure of structural reliability), respectively. In this case, the high nonlinearity in the structural response makes MCS method computationally expensive, for this reason, FORM algorithm is adopted here, which is based on Hasofer - Lind - Rackwitz - Fiessler (HLRF) iteration method in order to find the so-called Most 
Probable Point (MPP) [21]. The algorithm can handle correlated and non-normally distributed random variables. The coordinates of MPP are calculated on the basis of sensitivity of limit state function which is approximated with partial derivatives in every substep. Due to the complexity and discrete nature of the design problem and variables (e.g. thickness of the flange plate, thickness of insulation), partial derivatives can be calculated e.g. with central difference method, which means that the limit state function shall be evaluated a lot of times during the iteration. It makes the problem computationally expensive thus the use of FORM was preferable.

The failure of a steel frame structure can be caused by several failure mechanisms. Any of these failure modes occurs, it can be said that the investigated frame is failed, so the failure components compose a series reliability system, where the following approximation can be given for the boundaries of the failure probability [4]:

$\max _{i=1 . . n}\left\{P_{f, i}\right\} \leq P_{f, S} \leq 1-\prod_{i=1}^{n}\left(1-P_{f, i}\right)$

Where $P_{f, i}, n$ and $P_{f, S}$ are the failure probability related to the $\mathrm{i}^{\text {th }}$ failure mode, the number of failure modes and the failure probability of the system, respectively. When full correlation exists between the failure modes, the lower boundary for the failure probability is the maximum probability from the $\mathrm{n}$ cases. If the value of the limit state function can be calculated with respect to the all relevant components (failure modes) within reliability analysis simultaneously then the correlation between failure modes is already taken into account (as it is the case in this study).

In case of the whole structure that consists several frames, the reliability system is also series because in the case of failure of one frame we consider that the structure is failed. If the whole structure is modelled in the limit state function as a three-dimensional structure with respect for the random variables (and their correlation) of every individual frame, the correlation between the frames is already taken into consideration. However, the three-dimensional modelling of the system incredibly increases the complexity of the reliability calculation, thus the problem should be simplified and somehow 
approximated. Second is the application of simple bounds [4] or e.g. Ditlevsen bounds [44] to approximate the system reliability with respect to the correlation between the failures of separated frames. In this case the structural reliability of the frames has to be calculated individually first.

\section{LIMIT STATE FUNCTION}

\subsection{Modelling of the fire effects}

Realistic modelling of the fire effects is important in order get realistic value for structural reliability from the calculation. The most widely used representation of the fire effects in fire resistant design is the fire curve, which gives the temperature as a function of the time as it is illustrated in Fig. 2a.
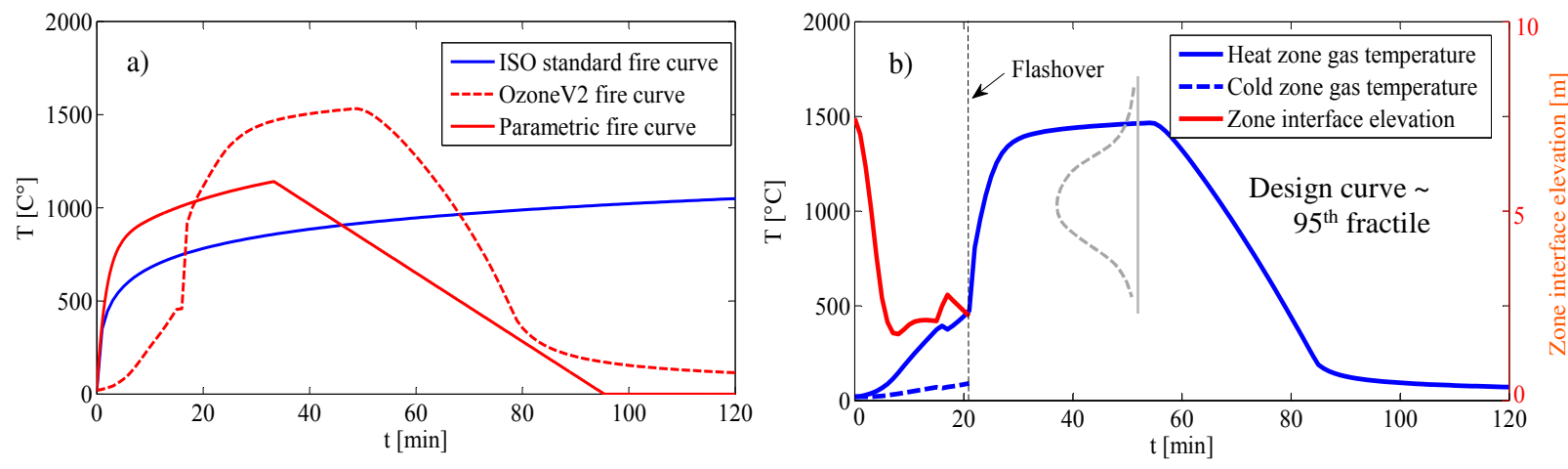

Fig. 2. - a) The shape of different fire curves; b) Design gas temperatures and zone interface elevation calculated in OZone V2.2.6

The authors suggest the usage of fire curves which are obtained on a stronger physical basis (e.g. OZone zone model [15] considers the amount and characteristics of the fire load) for the reliability calculation. The design fire curve related to the investigated problem can be seen in Fig. $2 b$. It is considered in the analysis that in the first period of the fire there are two different zones, namely hot and cold zones. The OZone software is able to calculate both temperatures and the interface elevation based on the energy and mass balance. After the flashover, the two-zone model is switched into one-zone model (Fig. 2b), which means that interface elevation is assumed to be zero and only the heat zone temperature curve is used for further calculation after $\sim 21 \mathrm{~min}$. As it will be described in Section 5.3., the applied finite element model gives the opportunity to consider spatial variation in the temperature element by element. The presented methodology (Fig. 1) is able to handle any kind of fire curve (e.g. ISO or parametric curves), however 
simplified curves do not relate strongly actual physical conditions. As studies shown earlier, e.g. [22, 10], the usage of ISO fire curve for fire resistant design can hardly ensure consistent reliability level, since the structural reliability depends on the function and properties of the fire compartment and on the amount and properties of the fire load.

The uncertainty in the fire effects is considered through the introduction of a global uncertainty factor that has been calculated by Monte Carlo Simulation. The second way is used in this study. Since the OZone [15] is not appropriate for evaluating numerous simulations, the uncertainty in the gas temperatures is obtained using parametric fire curves [1] with a little modification according to [23] in order to eliminate the discontinuity in the calculation (limits suggested by [1] for some parameters introduced to separate fuel and ventilation controlled fires cause an unreasonable discontinuity in the compartment temperatures). The investigated compartment can be found in the literature [7] $(6.4 \times 3.2 \times 2.6 \mathrm{~m}$ compartment with $4.4 \mathrm{~m}^{2}$ openings; mean fire load $420 \mathrm{MJ} / \mathrm{m}^{2}$ with $\mathrm{CoV}=0.3$ according to [1]). The maximum gas temperature is used as the output parameter of 100,000 simulations and it was found that the uncertainty in the maximum temperature can be approximated with a lognormal distribution (because the effect of uncertain parameters may be multiplied with each other), which has a mean equal to 1.0 and a $\mathrm{CoV}$ (Coefficient of Variation) equal to 0.25 . Uncertainty is considered in the fire load (Gumbel; $\mu=420$ $\mathrm{MJ} / \mathrm{m}^{2}, \mathrm{CoV}=0.3$ ), in the specific heat of concrete (Normal; $\mu=900 \mathrm{~J} / \mathrm{kgK}, \mathrm{CoV}=0.1$ ), in the thermal conductivity of concrete (Normal; $\mu=1.5 \mathrm{~W} / \mathrm{mK}, \mathrm{CoV}=0.1$ ) and in the calculation of a reduction factor $\zeta$ (as suggested in [24]) related to the opening factor (Lognormal; $\mu=0.2, \mathrm{CoV}=1.0$ ). Parametric fire curve are used to approximate the uncertainty since it was fitted on temperatures obtained by real fire tests [20]. It is clear that the calculation of the temperature is one of the key issues of fire design problem and there may not be method which could be used both effectively and accurately to calculate the maximum temperature. For this reason, the uncertainty in the temperature has to be analyzed more detailed in the further studies. 
This uncertainty is considered in the reliability analysis through the uncertainty of the steel temperatures as it is described in Section 5.2. For this reason the fire curve, as the input parameter of the analysis, has to be given as a representation of mean gas temperature. In order to calculate the mean fire curve, it was assumed that every point of the design curve is $95^{\text {th }}$ percentile of the above obtained lognormal distribution (Fig. 2b).

\subsection{Calculation of the steel temperature}

The rate of heating and maximal temperature of steel plates can be very different even in case of regular structural members due to the variation in the geometry or cross section, in the thickness of the insulation and different spatial location This variation in the structural temperature is more typical in case of complex structural systems and can cause a complex structural response. For this reason, the calculation of steel temperature has to be built in the limit state function. Furthermore, by using different temperature curve for every element, other scenarios (e.g. local fires) can be followed easily in the analysis.

According to EC3-1-2 [2] standard the steel temperature of an insulated element can be calculated as follows:

$\Delta \theta_{a, t}=\frac{\lambda_{p} A_{p} / V\left(\theta_{g, t}-\theta_{a, t-1}\right)}{d_{p} c_{a} \rho_{a}(1+\phi / 3)} \Delta t-\left(e^{\phi / 10}-1\right) \Delta \theta_{g, t}$

$\phi=\frac{c_{p} \rho_{p}}{c_{a} \rho_{a}} d_{p} A_{p} / V$

This is an incremental, time step formula, where $\mathrm{t}, \lambda_{p}, d_{p}, c_{p}, \rho_{p}, c_{a}, \rho_{a}$ and $A_{p} / V$ are the time, the thermal conductivity, thickness, specific heat, unit mass of insulation material, specific heat, unit mass of protected material and section factor of the protected section, respectively. The $\Delta \theta_{g, t}$ and $\Delta \theta_{a, t}$ are the gas and steel temperature at time step $t$. An equivalent thermal conductivity for intumescent coating can be approximated on the following way.

In case of intumescent coating there is not closed formula for calculating the steel temperatures. The design of the coating thicknesses is based on experimental results that have been obtained by furnace 
testing using ISO standard fire curve. We can assume that the listed data in the design sheets (e.g. in case of Polylack A, [25]) give the required thickness wherewith after 30, 45 or 60 minutes the steel temperature reaches exactly the critical temperature. Using this assumption and a suggestion from the European Convention for Constructional Steelwork (ECCS) for calculating equivalent thermal resistance [26], the following formula can be derived:

$$
\lambda=\frac{d}{R}=\frac{d}{\frac{A}{V}\left[\frac{t}{2400(T-140)}\right]^{\frac{1}{0.77}}}\left[\frac{W}{m K}\right]
$$

Where $\lambda, d$ and $A / V$ are the equivalent thermal conductivity, the thickness of intumescent coating and the section factor of the cross section, respectively. The equivalent thermal conductivity of the used protection material [25] is calculated for several cases using the design sheet from the Hungarian producer. In point of section factor, only a relevant range is used in the calculation $(\mathrm{A} / \mathrm{V}=160-300 \mathrm{1} / \mathrm{m})$, as it can be seen in Fig. 3a. It may practical to fit a continuous function on the observed data in order to extrapolate other cases which cannot be found in the design sheet. In case of the investigated protection material, the applicability of linear approximation for the equivalent conductivity is confirmed by Fig. 3a (the thickness of the intumescent coating and the section factor has to be substituted in $\mathrm{mm}$ and $1 / \mathrm{m}$, respectively).

The equation (5) is used in this study to calculate the steel temperature of every element in any time-step. The $\phi$ parameter is neglected due to the fact that: a) the equivalent properties of intumescent coating is uncertain; b) the $\phi$ is very close to zero; c) the thermal conductivity is obtained using experimental data so the actual performance of the insulation material is represented well.

In order to evaluate the uncertainty in the steel temperature, 50,000 MCS (which seems to be enough since only few parameters is considered) have been carried out similarly to the case of gas temperature. Based on the results of simulations carried out with Eq. (5), the uncertainty in the steel temperature at $\mathrm{t}=30 \mathrm{~min}$ is analysed. It seemed that lognormal distribution is fit well (Fig. 3b) which is not surprising since the dominant random variables were assumed to be lognormally distributed. 

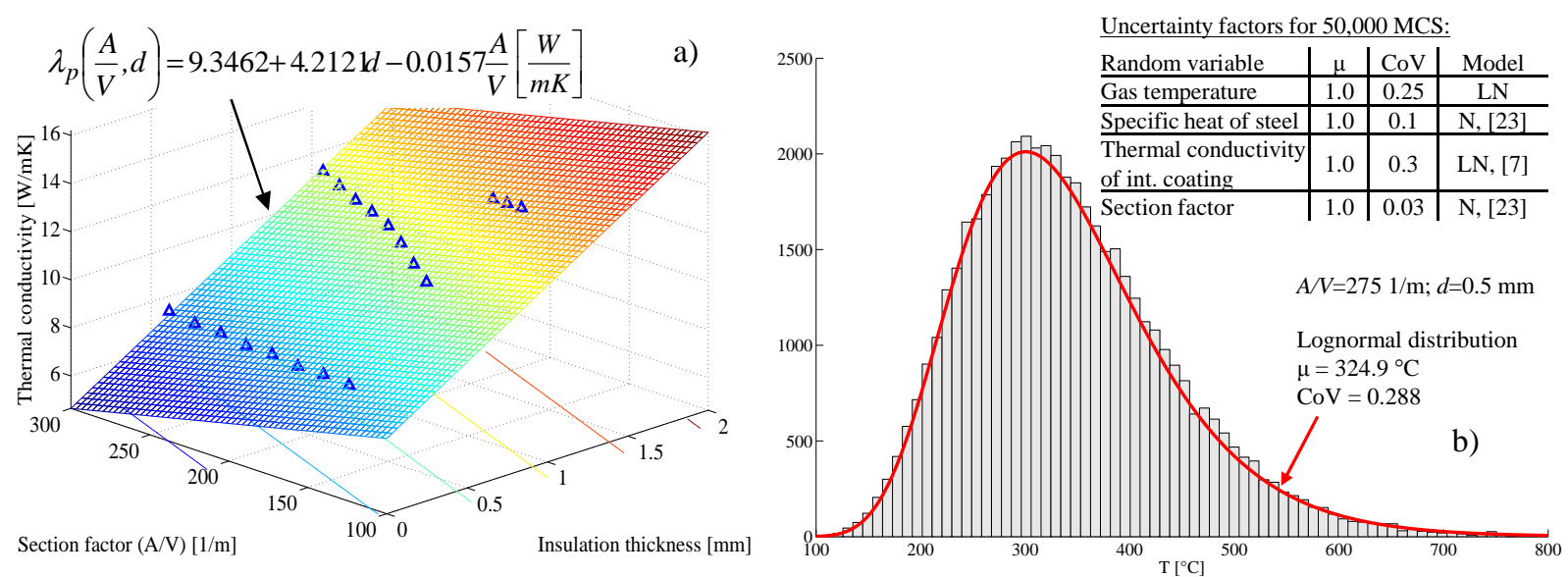

Fig. 3. - a) Equivalent thermal conductivity as a function of section factor and thickness; b) Uncertainty in the steel temperature

\subsection{Structural analysis}

The type of structural analysis and numerical model is an important issue from the point-of-view of reliability analysis of structures subjected to fire effects mainly because of the high nonlinearity in the thermal effects and in the structural response. The determination of the internal forces using one simple static analysis and a linear elastic structural model might not be reliable enough.

In parallel with the increasing the steel temperature, the strength and stiffness of steel are decreasing [2], this causes a complex, nonlinear structural response under fire exposure. The heating of the elements is clearly nonlinear, furthermore due to the differences in the heating intensity and the stiffness of different elements the internal forces redistribute during the heating. Time-step analysis is required to follow loadhistory-dependent response using a structural model that can represent the change in the stiffness during the analysis in case of elements, plates and fibres, as well. In this study, the time step of the numerical analysis is set to 10 seconds which means that the maximum number of steps is 720 , if 120 minutes is considered as relevant time interval exposed to fire effect.

The decreasing in the stiffness causes higher deformations under the loading, which effect has to be taken into account using geometrically nonlinear analysis. Materially nonlinear analysis gives the opportunity to account the plastic behaviour of the material, the elements and the structure really unfavorable effect of 
the decreasing in the stiffness is that the stability failure of the elements (e.g. buckling of plates, flexural torsional buckling of columns, etc.) becomes dominant failure modes. The stability resistance can be calculated using reduction factor method or using nonlinear analysis on imperfect structural model MSZ EN 1993-1-1:2009 (EC3-1-1) [27] which is typically referred as General Method according to [27]. In order to evaluate the structural reliability as accurate as possible, the nonlinear time-step analysis has to be built in reliability analysis through the limit state function.

In this study, an open source finite element code, namely OpenSees [28], is used with its OpenSeesThermal extension [29] analysing the nonlinear structural behaviour on high temperatures (with considering the temperature-dependent properties of steel material and the connections). For sake of simplicity, a two-dimensional structural model (Fig. 4a) is developed in OpenSees with equivalent geometrical imperfections (that involve the effect of the geometrical imperfections, structural imperfections, residual stresses, variation of the yield strength) according to [27]. The second frame from the system is modelled only with its loading conditions assumed that purlins are constructed as continuous beams. Due to the function of the investigated structure, it can be assumed that the stored combustible material is nearly uniformly distributed under the modelled frame, thus the gas temperature may also uniformly distributed. In order to represent well the response of a tapered frame, the column and beam elements are divided in the analysis into 10 and 20 smaller elements, respectively. Geometrically and Materially Nonlinear Imperfect (GMNI) analysis is carried out on the developed model. Using the calculated steel temperature for every sub-element, the analysis can follow the change in the properties of the steel material according to [2] and the development of additional internal forces from the constrained thermal expansion. 

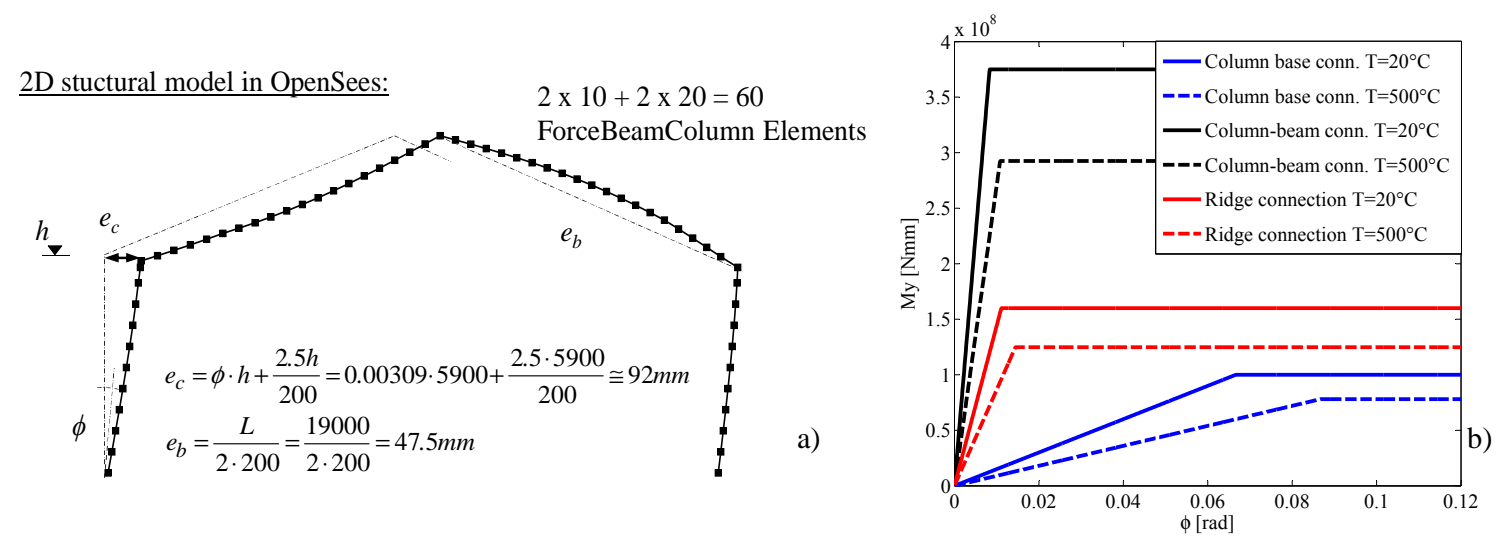

Fig. 4. - a) The imperfect 2D structural model in OpenSees; b) Bilinear material models for connections

The properties of the connections [30] are not variables in the analysis, their stiffness, strength and nonlinear behaviour (Fig. 4b) is modelled with nonlinear spring elements in the analysis. The temperaturedependent reduction factors have been calculated for stiffness and strength according to the recommendation of EC3-1-2 [2]. The connection properties are changed dynamically in the finite element analysis according to the calculated temperature of the connections.

The applied loads on the structure beside the fire effects are the dead load of the frame, sheeting and equipment (e.g. ventilation system) and the meteorological loads, namely wind and snow loads, calculated according to the EC1-1-2, MSZ EN 1991-1-3:2005 and MSZ EN 1991-1-4:2007 [1, 31, 32]. Due to the fact that not a specific frame is analyzed in this paper, there were no available data on the frequency of meteorological loads. For this reason, the distribution of one-year-maximums is calculated from characteristic values based on [31] and [32, 33, 34]. Similarly to [33], the Turkstra's approximation [24] (commonly used and conservative way to transform a time-variant problem into a time-invariant one) is applied for the combination of the time-variant loads, namely snow, wind and fire effects. The fire effect is been considered for 50 year service time as the dominant action. With the help of detailed statistical analysis on the intensity of meteorological loads (e.g. wind velocities, snow water equivalents) the accuracy of the calculation can be increased. As Sýkora showed in his study [33] on a similar problem, the 
above described approximation results in lower reliability indices then time-variant analysis, it is clearly conservative.

\subsection{Structural failure}

Based on the results of structural analysis, the value of the limit state function is evaluated related to the relevant failure modes. The considerable failure modes are usually problem specific. In case of the example structure, the investigated failure modes are the follows according to the regulations of EC3-1-1, EC3-1-2 and MSZ EN 1993-1-5:2012 [27, 2, 35]: a) strength or stability failure of beam or column elements; b) shear buckling of the web plates; c) plastic sway mechanism by the plasticity of the connections. In conformity with the fact that the elements (columns, beams, connections) of the frame can be considered as a series system, the maximum utilization is selected for the basis of the evaluation of the limit state function.

The stability verification of the beam and column elements is carried using the so-called General Method (GM) [27], where the in-plane stability failure is considered using imperfect structural model (Section 5.3.), while the out-of-plane stability failure is taken into consideration with reduction factors. The steps of checking stability failure are presented in Fig. 1 where $\chi_{o p}$ and $\alpha_{u l t, k}$ are the reduction factor taking into account the out-of-plane stability failure and the minimum load multiplier in order to reach the characteristic resistance of the critical cross section. The effect of elevated temperature is taken into account in both effect and resistance. The reduction factor is a function of the following non-dimensional slenderness:

$\bar{\lambda}_{o p}=\sqrt{\frac{\alpha_{u l t, k}}{\alpha_{c r, o p}}}$

In Eq. (7), $\alpha_{c r, o p}$ is the critical load amplifier in order to reach the critical intensity of internal forces causing out-of-plane flexural buckling or lateral torsional buckling, respectively. In this study, the critical bending moment for tapered steel member is calculated using an approximation from the literature [36], where calculation is based on an equivalent non-tapered element. The critical load amplifiers for different 
stability failures, namely flexural buckling (FB) and lateral torsional buckling (LTB), are combined with Dunkerley theorem [37] (which can be used as an approximate superposition technic of critical load amplifiers related to different loading conditions) in the following form:

$\alpha_{c r, o p}=\left(\frac{1}{\alpha_{c r, F B}}+\frac{1}{\alpha_{c r, L T B}}\right)^{-1}$

The $\alpha_{c r, F B}$ and $\alpha_{c r, L T B}$ are obtained considering the reduced stiffness of the steel material. The $\chi_{o p}$ is calculated as the minimum of the reduction factors related both of the flexural and lateral torsional buckling, because the interpolation is considered unsafe [38]. Both of these reduction factors are obtained using the global relative slenderness Eq. (7).

The decrease of the stiffness and strength has a significant unfavorable effect on the buckling resistance of the compressed plate elements, which has to be considered in case of the classification of the sections in every evaluation of the cross section resistances. According to [35], the $\varepsilon$ parameter of [2] for section classification can be formulated as follows:

$\varepsilon=\sqrt{\frac{k_{E}}{k_{f_{y}}}} \sqrt{\frac{235}{f_{y}}} \approx 0.85 \sqrt{\frac{235}{f_{y}}}$

The standard [35] approximates the effect of temperature in case of the section classification with a 0.85 multiplier, which actually underestimates the buckling capacity of the plate under $350{ }^{\circ} \mathrm{C}$ and overestimate it over $550{ }^{\circ} \mathrm{C}$. The derived formula is used in this study in case of the classification of cross sections.

The failure of the purlins and sheeting is not considered here, although they lose their load bearing capacity very early because of the thin wall and high section factor, but due to the relatively low loading and the possible catenary action [39] (similarly to composite floor slabs [40]) they may not fall down. The serious deformation and damage of sheeting seems unavoidable in fire design situation. 


\section{RELIABILTY CALCULATION OF A TAPERED STEEL FRAME}

\subsection{Example structure and deterministic fire design}

The investigated structure in this paper is a storage hall, which has altogether 8 frames, as it is shown in Fig. 5 where the important design parameters are also presented. The structure is divided into two parts; the first part is a small office, while the back part has the storage function. In this study the storage compartment is analyzed only. The tapered internal frames are welded, while the conventional frames at the end are made from hot rolled sections. The steel grade of the material of primary frames is selected for S355 structural steel. The columns are restrained against torsion approximately at the middle of the eave height, while there are altogether six brace element equally distributed in the roof level in order to support the compressed flange of the beam elements. At high temperatures, the sheeting and purlins cannot be considered as supports for the flanges, because they lose their stiffness very quickly because of the high section factor and the thin walls.

The frame has been designed first according to the prescriptive design rules of EC0, EC1-1-2 and EC3-1-2 $[16,1,2]$. The internal forces were obtained in extreme design situation, according to [16], using a materially linear imperfect model with geometrically nonlinear structural analysis. In the elastic analysis the initial stiffness of the connections was considered with the help of rotational spring elements at the base, the frame corner and the ridge (Fig. 6). In order to represent the stiffness of a tapered frame, the column and beam elements were divided in the analysis into 10 and 20 smaller elements (Fig. 4a), respectively. The temperature effects were considered in the analysis and summed with the gravity and meteorological forces. Since the sheeting system is supported by thin-walled purlin elements, it was assumed that the elements of the frame are heated from four sides. The equivalent geometrical imperfections were selected according to [5] in order to consider the in-plane stability failure. The out-ofplane buckling was considered with reduction factor, as it is described in Section 5.4. The connections were verified in terms of load bearing capacity (the resistance of the connections was obtained from [30]); 
shear buckling of the plates was also checked. According to the prescriptive design rules of $[1,2]$, the effects and resistances were compared on design values (considering the code suggested safety factors).

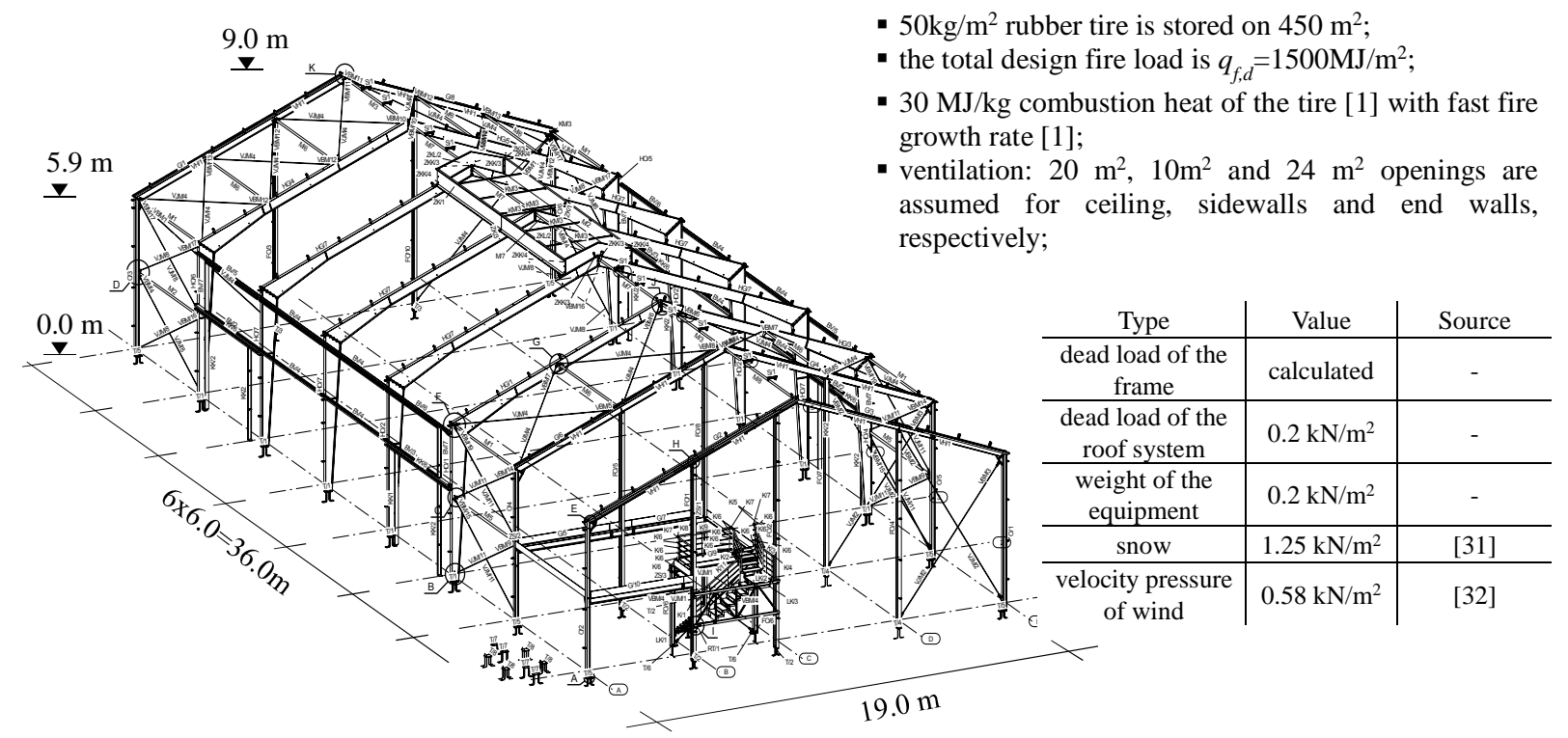

Fig. 5. - Investigated frame [41]

In order to calculate the critical temperature of the elements, the temperature has to be found where the utilization (demand to capacity ratio) of the element reaches 1.0 considering the reduced strength and stiffness of the steel material [2]. Due to the fact that the structure is reactive to stability failure, the process is iterative, however usually within $2-3$ iterative steps the critical temperature can be found with reasonable accuracy. Inherently, the structural analysis shall be repeated in every iteration step. The cross section properties, the critical temperature-related $\alpha_{c r, o p}, \alpha_{u l t, k}$ values and the calculated critical temperatures can be seen on Fig. 6 . The dominant failure mode of the elements was loss of stability. It can be seen, that that the original structure has been well designed because the critical temperatures show that the structure is almost uniformly utilized.

Intumescent coating fire protection is used more frequently in the last decades, for this reason, this type of protection is analysed in this paper. In case of the intumescent coating protection, typically the appropriate insulation thickness is simple selected knowing the critical temperature of the element (which can be 
obtained on the above described way) and the time demand (e.g. 15, 30 or 45 minutes) related to the load bearing capacity of the structure in fire. In Europe, the appropriate thicknesses are typically obtained according to EN 13381-8 standard [42], which prescribes furnace tests for the producers using standard ISO fire in order to exclude reaching the critical temperature in a given time for a specific section factor (the ratio of the heated surface and volume for an element) [2]. The intumescent paint of a Hungarian producer (Polylack A, [25]) is considered in this study, the thickness of the intumescent coating for each element (Fig. 6) has been calculated for 30 minutes fire resistance using data sheets given by producer of the intumescent coating. The cross sections of the elements are very slender; the section factor is between 250-310 1/m. The protection of the connections has been selected for $0.55 \mathrm{~mm}$.

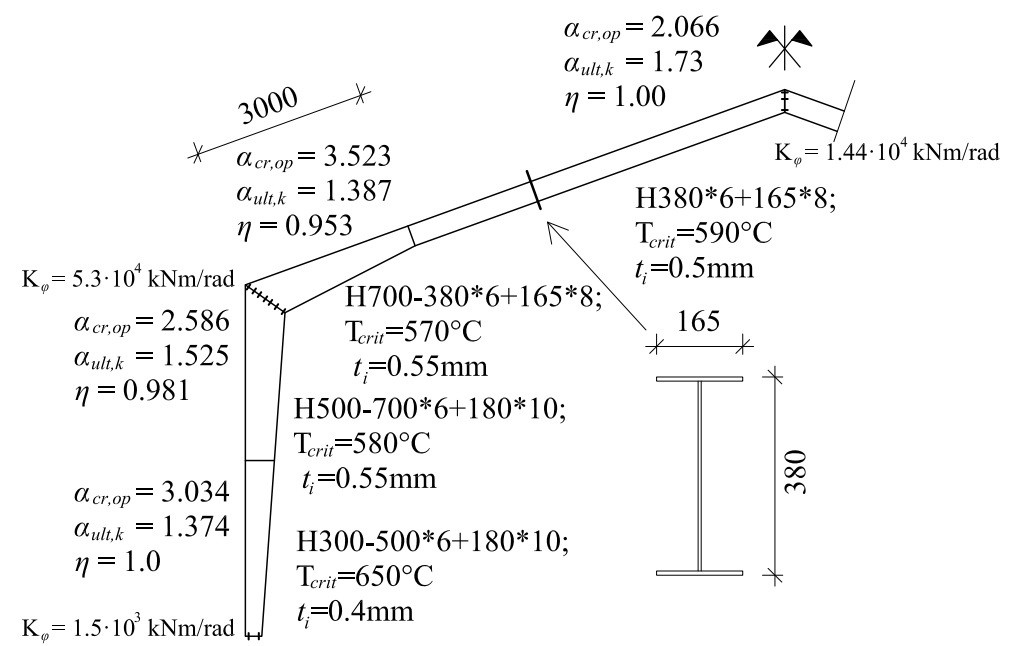

Fig. 6. - Section dimensions, utilization and calculated critical temperatures of the investigated frame

\subsection{Random variables}

The random variables, considered in the reliability analysis, are shown in Table 1 . The variability in the global geometry (building width, ridge height, etc.) is neglected since they have a small variation and they do not affect significantly the global behaviour. The mean value of the meteorological loads is calculated using distribution and $\mathrm{CoV}$ values from the literature [33 and 34] and the assumption that the characteristic values are related to $98^{\text {th }}$ percentile of the distributions one-year maximums $[31,32]$.

Uncertainty factors are related to the resistance of the bolted connections according to the JCSS Probabilistic Model Code [24]. Respect to the variability of cross sections, different uncertainty factors are 
considered for beams and columns, respectively. The sections are welded and the part of tapered elements, thus a little bit higher CoV values can be found in Table 1., than it is suggested in [24].

\begin{tabular}{|c|c|c|c|c|}
\hline Random Variable & $\mu$ & $\mathrm{CoV}$ & Distribution & Reference \\
\hline Yield stress [MPa] & 388 & 0.07 & Lognormal & {$[24]$} \\
\hline Equipment $\left[\mathrm{kN} / \mathrm{m}^{2}\right]$ & 0.2 & 0.2 & Normal & \\
\hline Wind load $\left[\mathrm{kN} / \mathrm{m}^{2}\right]$ & 0.252 & 0.5 & Gumbel & Calculation, $[32,33]$ \\
\hline Snow load $\left[\mathrm{kN} / \mathrm{m}^{2}\right]$ & 0.444 & 0.7 & Gumbel & Calculation, $[31,34]$ \\
\hline $\begin{array}{l}\text { Resistance factor for the column-base } \\
\text { connection }[-]\end{array}$ & 1.25 & 0.15 & Lognormal & {$[24]$} \\
\hline $\begin{array}{l}\text { Resistance factor for the column-beam } \\
\text { connection [-] }\end{array}$ & 1.25 & 0.15 & Lognormal & [24] \\
\hline $\begin{array}{l}\text { Resistance factor of ridge beam-beam } \\
\text { connection [-] }\end{array}$ & 1.25 & 0.15 & Lognormal & [24] \\
\hline Right column section modulus factor [-] & 1 & 0.05 & Normal & [24] \\
\hline Left beam section modulus factor [-] & 1 & 0.05 & Normal & [24] \\
\hline Right beam section modulus factor [-] & 1 & 0.05 & Normal & [24] \\
\hline Effect model uncertainty factor [-] & 1 & 0.15 & Lognormal & \\
\hline Resistance model uncertainty factor [-] & 1 & 0.2 & Lognormal & \\
\hline Steel temperature uncertainty factor [-] & 1 & 0.3 & Lognormal & Calculation \\
\hline
\end{tabular}

Table 1. - Random variables

Model uncertainty factors are taken into account on both effect and resistance sides. $\mathrm{CoV}=0.15$ value in the calculation of the internal forces accounts the uncertainty caused by the finite element modelling of the tapered frame and the stiffness of the connections. The presented value fits well to [24]. The resistance model uncertainty factor has much higher variability than it is suggested in the literature for single cross section in bending, because of the interaction among different failure modes, thermal effects affect the cross section resistance and stability failure, imperfections and calculation of stability resistance of tapered elements. In case of steel temperature, a lognormal uncertainty factor with $\mathrm{CoV}=0.3$ is considered (Section 5.2). Other configurations have been also investigated similarly to the presented case and it was found that the $\mathrm{CoV}$ can be approximately selected equal to 0.3 related to the properties of the investigated frame.

As it was presented before, for the sake of simplicity a two-dimensional structural model is applied in the reliability analysis thus the failure probability of the system is considered to be equal with the failure probability of the second frame which has maximum failure probability. For this reason no random variables are presented in Table 1 related to different portal frame within the system. This approximation means that full correlation is assumed among the frames. However, it has to be noted that if the correlation 
is not full but the correlation coefficient equals to 0.8 or 0.9 among the frames, the failure probability of the whole system can be 4 or 3 times bigger than in the case of full correlation, respectively. This issue is not covered in this paper because the aim of the presented calculation is only the demonstration of the proposed methodology. However, this issue should be further investigated in following studies which are dealing with the structural reliability calculation of portal frame systems.

\subsection{Results of reliability analysis}

Related to the example storage hall, the results of reliability analysis using FORM are summarized in Fig. 7 where the convergence of the proposed algorithm is also presented. The results indicate a fast convergence and stability of the presented methodology and the adherent FORM algorithm. The iteration and the calculation of partial derivatives cause the fluctuation in the reliability index during the convergence.

The calculated reliability index for 30 minutes fire resistance is $\beta_{\text {fai }} \approx 3.3\left(\mathrm{P}_{\text {fail }}=4.83 \cdot 10^{-4}\right)$ with a conditional reliability index equals to $\beta_{\text {failffashover }}=0.594\left(\mathrm{P}_{\text {failfflashover }}=0.2763\right)$. It can be said that the reliability index related to the failure barely satisfies the criteria of EC0 [16] for $\mathrm{CC} 1$ consequence class with target value for the reliability index equals to 3.3. In JCSS [24] for low and moderate consequences target values for 50 years are equal to cca. 2.55 and 3.21 respectively. For this reason, it can be concluded that the structure has enough reliability for 30 minutes demand against failure under fire exposure. It has to be noted that because of the applied Turkstra's approximation the presented value for the reliability index is a conservative estimation. Using more accurate superposition of time-variant meteorological loads higher structural reliability can be achieved.

The conditional probability is relatively high; the main reason is that the structure can satisfy the criterion is that the occurrence of a severe fire for 50 years is tolerably low. This is resulted partially by the usage of active safety measure, like an alarm system, which causes significant reduction in the occurrence of severe fire according to the literature $[19,20]$. Without the application of active safety measure, the structure definitely could not satisfy the criteria of [16]. 
The sensitivity factors of FORM (Fig. 7) emphasize the most important random variables which influence mostly the resulted value of the reliability index. In case of the investigated frame these variables are value of the snow load, the section modulus-, steel temperature-, effect- and resistance model uncertainty factor. The reliability is hardly or not sensitive for the yield stress, for the gravity load, for the wind load and for the resistance uncertainty factors related to the capacity of connections. Much higher temperature is needed for plastic sway mechanism failure mode than e.g. lateral torsional buckling of the beam elements due to the fact that the frame is sensitive for stability failure modes.

\begin{tabular}{|c|c|c|}
\hline Random Variable & $\begin{array}{l}\text { Sensitivity } \\
\text { factors }-\alpha\end{array}$ & $\begin{array}{l}\text { Value at the } \\
\text { MPP point }\end{array}$ \\
\hline Yield stress [MPa] & -0.0914 & 386.81 \\
\hline Equipment $\left[\mathrm{kN} / \mathrm{m}^{2}\right]$ & 0.1007 & 0.201 \\
\hline Wind load $\left[\mathrm{kN} / \mathrm{m}^{2}\right]$ & 0.1177 & 0.238 \\
\hline Snow load $\left[\mathrm{kN} / \mathrm{m}^{2}\right]$ & 0.5633 & 0.481 \\
\hline $\begin{array}{l}\text { Resistance factor for the column-base } \\
\text { connection [-] }\end{array}$ & 0 & 1.241 \\
\hline $\begin{array}{l}\text { Resistance factor for the column-beam } \\
\text { connection }[-]\end{array}$ & 0 & 1.241 \\
\hline $\begin{array}{l}\text { Resistance factor of ridge beam-beam } \\
\text { connection [-] }\end{array}$ & 0 & 1.241 \\
\hline Right column section modulus factor [-] & 0 & 1 \\
\hline Left beam section modulus factor [-] & 0 & 1 \\
\hline Right beam section modulus factor [-] & -0.1852 & 0.995 \\
\hline Effect model uncertainty factor [-] & 0.4285 & 1.029 \\
\hline Resistance model uncertainty factor [-] & -0.4312 & 0.930 \\
\hline Steel temperature uncertainty factor [-] & 0.4965 & 1.048 \\
\hline
\end{tabular}

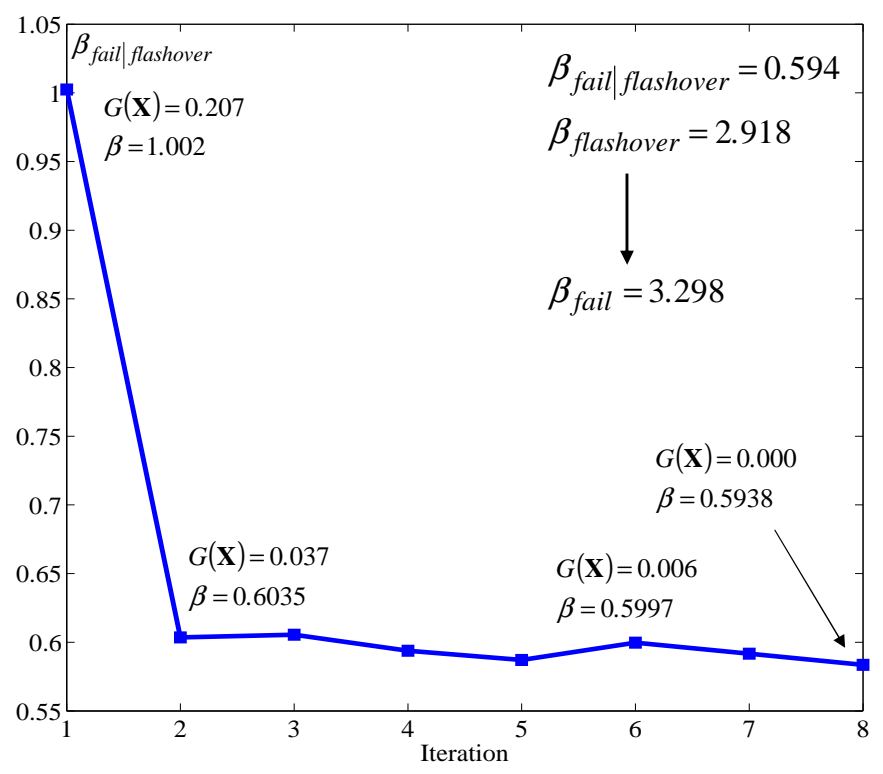

Fig. 7. - Convergence of the FORM algorithm in the reliability analysis

The dominant failure mode was stability failure of the right beam in the reliability analysis. This can be also observed from the value of the sensitivity factors in Fig. 7 and in Fig 8 where occurrence of different failure modes is presented on design gas temperature curve related to MPP. The shear buckling and failure of the web plates is not dominant in case of the example structure. It can be observed that the simplest way to increase the structural reliability is the strengthening of the beams. By slightly change of the beam flange $(\mathrm{b}=180 \mathrm{~mm})$ almost a $20 \%$ reduction can be achieved, the conditional reliability index equals to $\beta_{\text {failfflashover }}=0.736\left(\mathrm{P}_{\text {failffashover }}=0.2309\right)$. The reliability is not sensitive for other section modulus uncertainty factors; this is partly resulted by the rounding in the limit state function because of the finite number of 
applied time steps. It can be concluded that the stiffness of columns and of the other beam has not a significant effect on the failure of the right beam at MPP.

The reliability analysis is carried out for 30 time demand using ISO standard fire curve in order to characterise the difference in the structural reliability. The calculated conditional reliability index equals to $\beta_{\text {failffashover }}=0.7\left(\mathrm{P}_{\text {failfflashover }}=0.242\right)$ which results $\beta_{\text {fai }} \approx 3.34$ unconditional reliability index. It seems that the results are in a good agreement, the difference is only 13\%, although ISO standard fire curve is not a realistic effect but only a comparable one. Analysing Fig. 2, it can be observed that at 30 minutes time demand the two fire curves have approximately the same integral, which means that the released heat energy is almost the same in case of both curves. This would not be true in case of different time demands (e.g. 15 and 45 minutes; see Fig. 2) and in case of quantitatively and qualitatively different combustible material, significant differences may be observed in these cases in the structural reliability. It can be concluded that design parameters (e.g. amount of combustible material, size of the compartment) affect the results of the reliability analysis because the fire curve changes. For this reason, consistent reliability level may hardly be achieved by the use of a comparable fire effect, like ISO standard fire curve, in far different design cases.

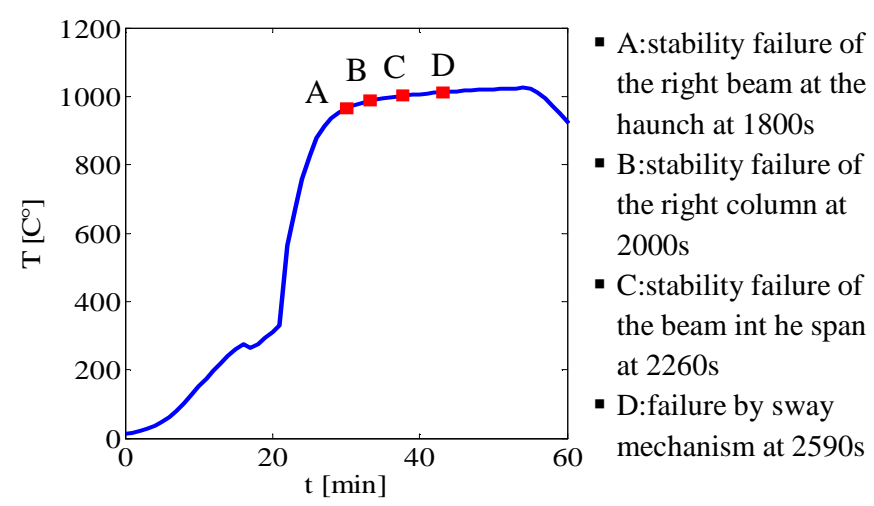

Fig. 8. - Occurrence of different failure modes 


\subsection{Validation with Monte Carlo Simulation}

In order to validate the method and to check the accuracy of FORM in reliability analysis of structures exposed to fire, the results are compared with MCS results. This validation is important because Guo and Jeffers have pointed in that FORM can significantly differ from MCS by similar problems (reliability analysis of a column under fire exposure [6]). On the whole, 100,000 simulations (since the conditional probability is relatively high, lower number of simulations enough for reasonable accuracy) have been carried out for comparison, which is made at 30 minutes fire resistance time. LHS is applied in order to ensure that the calculation is accurate at lower probabilities as well. Fig. 9 summarizes the results as a function of three variables, which influenced mostly the calculated reliability in the previous analysis. First of all, a nonlinear and a linear function can be seen on the figure as approximations around the MPP. The nonlinear function is fitted using regression on MCS results for which the value of the limit state function is between $-0.01 \leq G(\mathbf{X}) \leq 0.01$ (other constraints can be seen in Fig. 9). The linear multivariate function is from the last iteration of the earlier evaluated FORM (Fig. 8). The plane contains MPP and its normal vector can be calculated from the sensitivity factors.

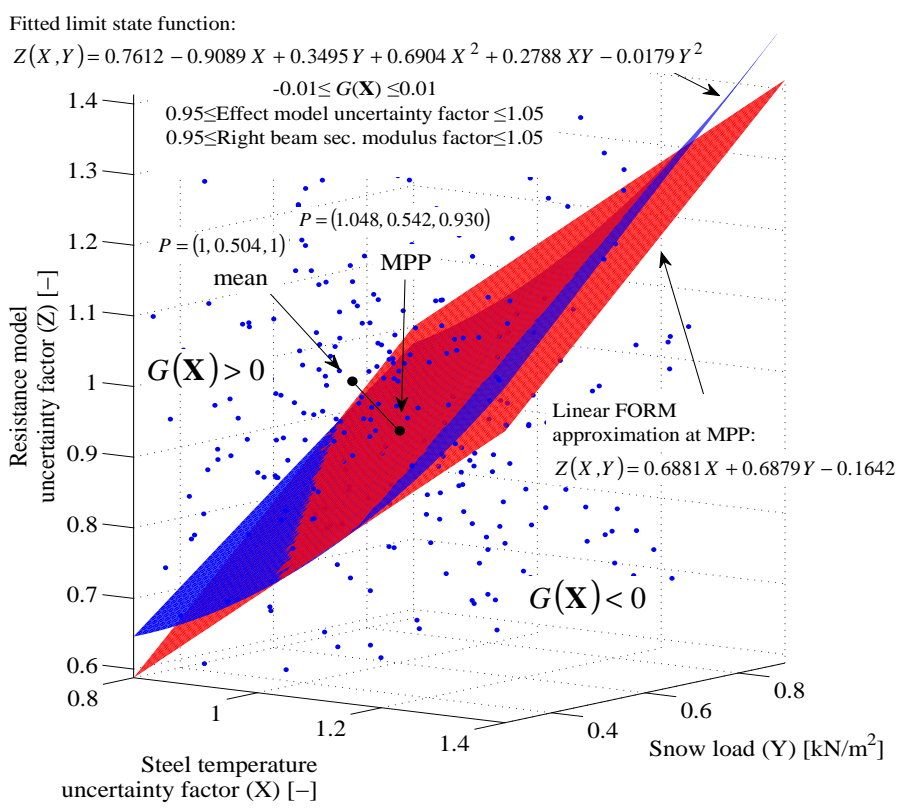

Fig. 9. - Linear FORM approximation of the Limit State Function at MPP 
As it can be seen in the Fig. 9, the FORM at the MPP (Maximum Probability Point) approximates well the fitted nonlinear limit state function, which was obtained by regression. This accuracy is mainly confined to a finite region around the MPP and farther from the MPP it is worse. For this reason, it is expected to have some difference between the calculated probabilities with FORM and MCS. The conditional failure probability for 30 minutes, calculated with $\mathrm{FORM}$, is equal to $\mathrm{P}_{\text {failfflashover }} \approx 0.276$, while the MCS gives $\mathrm{P}_{\text {failfflashover }} \approx 0.304$. It means that in the investigated case the FORM underestimates the failure probability with 9.3\%. Guo and Jeffers observed that the FORM overestimates the probability; however in [6] the difference was quite significant contrary to this calculation. It is clear that the accuracy of reliability calculation depends on the type and formulation of limit state function as well, not just on the accuracy of the evaluation technic.

Due to the fact that the FORM approximation can be less accurate in case of lower and higher failure probabilities, the results are compared using different time demands with the results of MCS. Although the example structure is verified against 30 minutes severe fire, the same structure is used in case of every time demand. The results are summarized in Fig. 10, where the results of FORM and fitted lognormal cumulative distribution function are also presented. Although tens of thousands of evaluation of the limit state function have to be carried out in one reliability analysis, in case of 30 minutes time demand the evaluation time of a FORM was only a bit more than 6 minutes, while the evaluation of a MCS took about 80 hours.

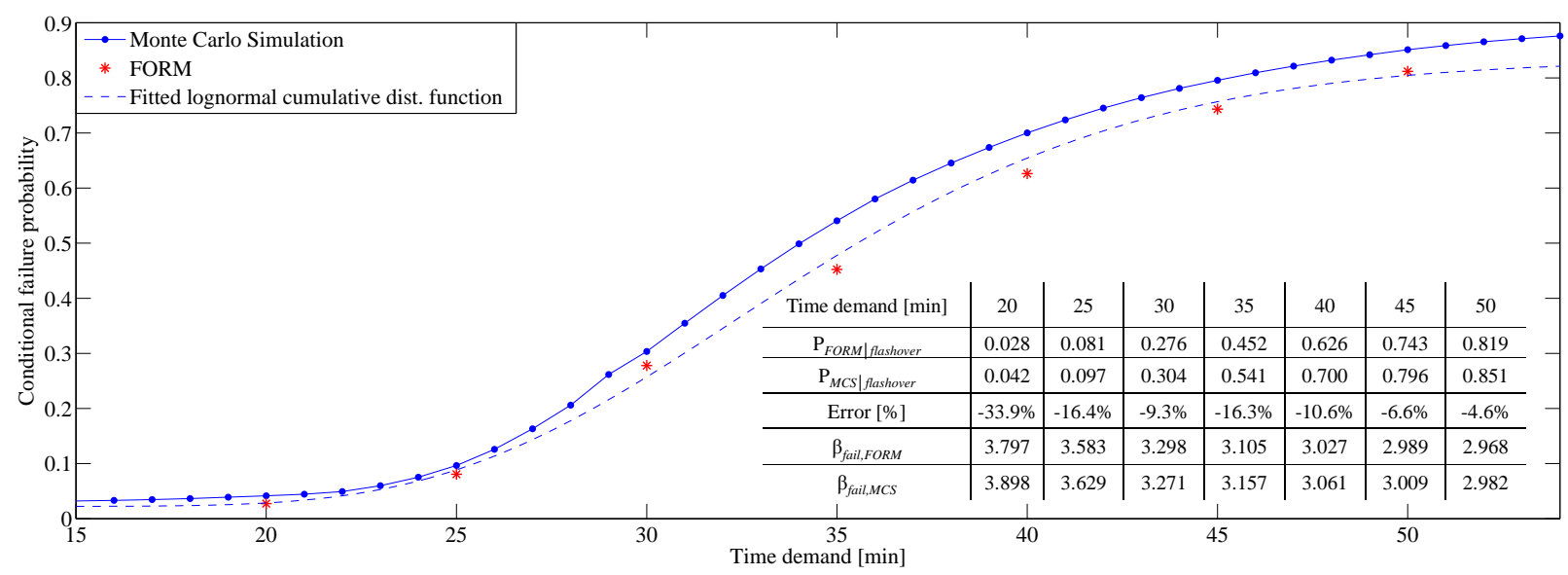


Fig. 10. - Conditional probabilities related to structural failure from FORM and MCS

It seems from the results of reliability analyses that FORM approximation underestimates the failure probability by all of the investigated cases. However, it is favourable that the error is not significant, since in case of highly nonlinear limit state functions the difference can be much higher than it was observed in case of the presented example. The reliability of the system is calculated only till 54 minutes because after that the fire starts to decay thus without intervention during the fire, the survival probability of the frame is $10-15 \%$.

The accuracy of the analysis can be increased with refinement of the time steps in the structural analysis and with the application of higher order approximation technic, e.g. SORM. However, the framework which was presented through this paper can be applied with these modifications without any problem.

\section{CONCLUSIONS}

In this paper a general framework is presented for reliability analysis of structures subjected to fire effects. The presented methodology gives a more reliable basis for the calculation of the reliability, the main differences are between the presented and earlier reliability calculations in the literature: a) the reliability calculation and the performance evaluation does not focuses on one single element but the whole structure, thus the reliability is calculated for the structural system; b) the presented methodology is able to consider more realistic circumstances than simple ISO fire [43] or t-equivalent concept according to [1]; c) reliability analysis contains the nonlinear analysis of the structure, in this way the highly nonlinear structural response is followed through the reliability calculation; d) the structural reliability is assessed on time basis. Similar complex framework has not been presented before for structural systems in the available literature. Among the input data, any kind of fire curves can be selected, thus more realistic and various circumstances can be easily considered in the calculation. The interaction between the elements and between different variables is taken into account by the evaluation of the nonlinear response of the structure within the limit state function. The degradation in the properties of steel material and connections is followed by the application of a time-step evaluation with tens of thousands of evaulation 
of the limit state function within one FORM. The reliability is assessed on time basis (as the most important measure in fire resistant design) which allows simpler formulation of the problem and provides a practical and informative basis for the designer. The accuracy of the calculation can be increased by decreasing the time step in the analysis; however, it increases also the evaluation time.

As an example, reliability analysis of a tapered portal frame protected by intumescent coating is presented in this study in order to demonstrate the application and the effectiveness of the proposed methodology. The investigated frame is a tapered storage hall where rubber tire is stored. It makes the design task demanding, the observable gas temperature can reach cca. $1500{ }^{\circ} \mathrm{C}$ on design value according to the results of two-zone fire model in OZone [15]. A simple formulation, which is based on [26], the steel temperatures can be assessed at any time step. The uncertainty of the fire action is built in the calculation through the uncertainty of the steel temperature, which is obtained with the help of MCS. The designed frame satisfies the criteria of EC0 [16] for $\mathrm{CC} 1$ consequence class for the demand which has been considered by its design. In case of the investigated frame the most influencing variables were the value of snow load, the section modulus-, steel temperature-, effect- and resistance model uncertainty factor.

The structural reliability against fire depends on the function of the investigated facility and on the quantity of combustible materials. For this reason, fire resistance practice based on the usage of equivalent fire effects (e.g. ISO fire curve) may not be able to ensure consistent reliability level in case of different design cases.

The presented reliability analysis is based on the application of FORM, whose computation time for a reliability analysis was approximately 6 minutes. The resulted failure probability is checked with the help MCS where the evaluation of the all simulated cases took 80 hours on the same personal computer. This verification is done for several time demands for the same portal frame which has been designed for 30 minutes fire exposure. It was found that the FORM approximation underestimates the failure probability because of the linear approximation of limit state function at MPP. The difference between the results of FORM and MCS was observed from $-4 \%$ to $-34 \%$ (Fig. 10), however the errors are not significant though 
the problem is highly nonlinear. For this reason, it can be said that the proposed framework is efficient and reasonable accurate because in some cases the difference can be much higher between the two technics (e.g. in $[6])$.

\section{ACKNOWLEDGEMENT}

This paper was supported by the János Bolyai Research Scholarship of the Hungarian Academy of Sciences. The presented results are part of the "HighPerFrame" R\&D project Nr. GOP-1.1.1-11-20120568, supported by the Új Széchenyi Terv.

\section{REFERENCES}

[1] MSZ EN 1991-1-2:2005, Eurocode 1, Actions on structures - Part 1-2: General actions - Actions on structures exposed to fires, Hungarian Standards Institution, Budapest, Hungary.

[2] MSZ EN 1993-1-2:2013, Eurocode 3, Design of steel structures - Part 1-2: General rules - Structural fire design, Hungarian Standards Institution, Budapest, Hungary.

[3] H. Gulvanessian, M. Holickỳ, L. G. Cayot, Reliability analysis of a steel beam under fire design situation, Proceedings of Eurosteel 1999 Conference, pp. 177-180, Czech Republic, Prague, 1999.

[4] M. H. Faber, Risk and Safety in Engineering - Lecture notes, ETH Zürich, 2009.

[5] Q. Guo, K. Shi, Z. Jia, A. E. Jeffers, Probabilistic Evaluation of Structural Fire Resistance, Journal of Fire Technology, Springer. 49 (2013), 793-811.

[6] Q. Guo, A. E. Jeffers, Finite-Element Reliability Analysis of Structures Subjected to Fire, Journal of Structural Engineering, ASCE. 141-4 (2015).

[7] C. Zhang, G. Q. Li, Y. C. Wang, Probabilistic Analysis of steel columns protected by intumescent coatings subjected to natural fires, Structural Safety 50(2014) 16-16.

[8] D. Lange, S. Devaney, A. Usnami, An application of the PEER performance based earthquake engineering framework to structures in fire, Engineering Structures 66(2014) 100-115.

[9] I. Boko, N. Torić, B. Peroš, Probabilistic analysis of the fire resistance of a steel roof structure exposed to fire, in: G. Deodatis, B. R. Ellingwood, D. M. Frangopol (Eds.), Safety, Reliability, Risk and Life-Cycle Performance of Structures and Infrastructures, Taylor \& Francis Group, London, 2013, pp. 4361-4366.

[10] I. Boko, B. Peroš, N. Torić, Reliability of Steel Structures under Fire Conditions, Proceedings of the $6^{\text {th }}$ International Seminar on Fire and Explosion Hazards, pp. 1-12, Leeds, United Kingdom, 2010.

[11] C. D. Eamon, E. Jensen, Reliability analysis of prestressed concrete beams exposed to fire, Engineering Structures 43(2012) 69-77.

[12] C. D. Eamon, E. Jensen, Reliability analysis of reinforced concrete columns exposed to fire, Fire Safety Journal 62(2013) 221-229.

[13] C. D. Eamon, E. Jensen, Reliability Analysis of RC Beams Exposed to Fire, Journal of Structural Engineerig, 139(2013) 212-220.

[14] R. V. Colie, R. Caspeele, L. Taerwe, Reliability-based evaluation of the inherent safety presumptions in common fire safety design, Engineering Structures 77(2014) 181-192.

[15] J. F. Cadorin, D. Pintea, J. M. Franssen, The Design Fire Tool OZone V2.0 - Theoretical Description and Validation On Experimental Fire Tests, $1^{\text {st }}$ draft, University of Liege, Belgium, 2001.

[16] MSZ EN 1990:2011, Eurocode 0, Basis of structural design, Hungarian Standards Institution, Budapest, Hungary.

[17] M. Holicky, J. B. Schleich, Modelling of a Structure under Permanent and Fire Design Situation, Proceedings of Safety, Risk and Reliability - Trends in Engineering International Conference, pp. 1001-1006, Malta, 2001.

[18] K. Tillander, Utilisation of Statistics to Assess Fire Risks in Buildings, PhD dissertation, Helsinki University of Technology, 2004. 
[19] DIFISEK Program: Dissemination of Fire Safety Engineering Knowledge documents - WP1 Thermal and mechanical actions.

[20] Leonardo da Vinci Pilot Project, Implementation of Eurocodes - Design of Buildings for the Fire Situation effects for buildings (Handbook 5), Luxemburg, 2005.

[21] S. K. Choi, R. V. Grandhim, R. A. Canfield, Reliability-based Srtuctural Design, Springer-Verlag, London, 2007.

[22] T. Balogh, L. G. Vigh, Reliability calculation of portal frame structures exposed extreme loading conditions with First Order Reliability Method (in Hungarian), Proceedings of $12^{\text {th }}$ Hungarian Conference on Mechanics (XII. MAMEK), Miskolc, Hungary, 2015.

[23] S. R. Hamilton, Performance-Based Fire Engineering for Steel Framed Structures: A Probabilistic Methodology, PhD Dissertation, Stanford University, 2011.

[24] Joint Committee on Structural Safety (JCSS), Probabilistic Model Code, 2000.

[25] Dunamenti Ltd., Technical data sheet of Polylack A intumescent painting (in Hungarian), http://www.dunamenti.hu/.

[26] European Commission for Constructional Steelwork (ECCS), Design manual on the European recommendation for the fire safety of steel structures, Brussels, 1985.

[27] MSZ EN 1993-1-1:2009, Eurocode 3, Design of steel structures - Part 1-1: General rules and rules for buildings, Hungarian Standards Institution, Budapest, Hungary.

[28] The Open System for Earthquake Engineering Simulation, http://opensees.berkeley.edu/.

[29] Opensees Developers Group of University of Edinburgh, OpenSeesThermal, www.wiki.ed.ac.uk/display/opensees/UoE+OpenSees

[30] L. Horváth, B. Kövesdi, Innovative design methods and solutions in fore design of steel frames (in Hungarian), MAGÉSZ Steel Structures, $1^{\text {st }}$ special issue, 50-60.

[31] MSZ EN 1991-1-3:2005, Eurocode 1, Actions on structures - Part 1-3: General actions - Snow loads, Hungarian Standards Institution, Budapest, Hungary.

[32] MSZ EN 1991-1-4:2007, Eurocode 1, Actions on structures - Part 1-4: General actions - Wind loads, Hungarian Standards Institution, Budapest, Hungary.

[33] M. Sỳkora, Reliability Analysis of a Steel Frame, Acta Polytechnica 42(2002) 27-34.

[34] Leonardo da Vinci Pilot Project, Implementation of Eurocodes - Action effects for buildings (Handbook 3), Aachen, 2005.

[35] MSZ EN 1993-1-5:2012, Eurocode 3, Design of steel structures - Part 1-5: Plated structural elements, Hungarian Standards Institution, Budapest, Hungary.

[36] A. Andrade, D. Camotim, P. Providência, Critical moment formulae for doubly symmetric web-tapered I-section steel beams acted by ending moments, Proceedings of the $4^{\text {th }}$ European Conference on Steel and Composite Structures, Eurosteel 2005, pp. 1.2-135-1.2-143, Maastricht, Netherlands, 2005.

[37] L. Kollár, Structural Stability in Engineering Practice, Taylor \& Francis, London, 2008.

[38] European Commission for Constructional Steelwork (ECCS) Technical Committee 8 - Structural Stability, Resolution of ECCS/TC8 with respect to the general method in EN 1993-1-1, 2006.

[39] P. J. Moss, R. P. Dhakal, M. W. Bong, A. H. Buchanan, Design of steel portal frame buildings for fire safety,Journal of Constructional Steel Research, 65(2009) 1216-1224.

[40] N. J. K. Cameron, A. S. Usmani, New design method to determine the membrane capacity of laterally restrained composite floor slabs in fire Part 1: theory and method. The Structural Engineer 83(2005) 28-33.

[41] T. Balogh, L. G. Vigh, Optimal design of tapered steel portal frame structures subjected to fire effects (in Hungarian), MAGÉSZ Steel Structures, $1^{\text {st }}$ special issue, $84-94$

[42] EN 13381-8:2013. Test methods for determining the contribution to the fire resistance of structural members - Part 8: Applied reactive protection to steel members, CEN, Brussels.

[43] ISO 834 - 10: 2014. Fire resistance tests - Elements of building constructions.

[44] O. V. Ditlevsen, Narrow reliability bounds for structural systems, Journal of Structural Mechanics, 4(1979), 453-472. 